\title{
Decreased Administration of Life-Sustaining Treatment just before Death among Older Inpatients in Japan: A Time-Trend Analysis from 2012 through 2014 Based on a Nationally Representative Sample
}

\author{
Michi Sakai ${ }^{1,2,3, *} \mathbb{0}$, Shosuke Ohtera $\left.{ }^{1,2}{ }^{(}\right)$, Tomohide Iwao ${ }^{2}(0)$, Yukiko Neff ${ }^{1,2}$, Tomoe Uchida ${ }^{1}$, \\ Yoshimitsu Takahashi ${ }^{1}$, Genta Kato ${ }^{4}$, Tomohiro Kuroda ${ }^{2}{ }^{1}$, Shuzo Nishimura ${ }^{3}$, Takeo Nakayama ${ }^{1}$ and on behalf \\ of BiDAME (Big Data Analysis of Medical Care for the Elderly in Kyoto) ${ }^{\dagger}$
}

check for updates

Citation: Sakai, M.; Ohtera, S.; Iwao, T.; Neff, Y.; Uchida, T.; Takahashi, Y.; Kato, G.; Kuroda, T.; Nishimura, S.; Nakayama, T.; Decreased Administration of Life-Sustaining Treatment just before Death among Older Inpatients in Japan: A

Time-Trend Analysis from 2012 through 2014 Based on a Nationally Representative Sample. Int. J. Environ. Res. Public Health 2021, 18, 3135. https://doi.org/10.3390/ ijerph18063135

Academic Editor: Paul B. Tchounwou

Received: 14 February 2021

Accepted: 13 March 2021

Published: 18 March 2021

Publisher's Note: MDPI stays neutral with regard to jurisdictional claims in published maps and institutional affiliations.

Copyright: (c) 2021 by the authors. Licensee MDPI, Basel, Switzerland. This article is an open access article distributed under the terms and conditions of the Creative Commons Attribution (CC BY) license (https:/ / creativecommons.org/licenses/by/ $4.0 /)$.
1 Department of Health Informatics, Kyoto University School of Medicine and Public Health, Kyoto 606-8501, Japan; ootera.s.aa@niph.go.jp (S.O.); yukik24jp@yahoo.co.jp (Y.N.); uchida.tomoe.22s@st.kyoto-u.ac.jp (T.U.); takahashi.yoshimitsu.3m@kyoto-u.ac.jp (Y.T.); nakayama.takeo.4a@kyoto-u.ac.jp (T.N.)

2 Division of Medical Information Technology and Administration Planning, Kyoto University Hospital, Kyoto 606-8507, Japan; tomohide@kuhp.kyoto-u.ac.jp (T.I.); tomo@kuhp.kyoto-u.ac.jp (T.K.)

3 Department of Research, Institute for Health Economics and Policy, Tokyo 105-0003, Japan; shuzo@soleil.ocn.ne.jp

4 Solutions Center for Health Insurance Claims, Kyoto University Hospital, Kyoto 606-8507, Japan; qq9f8hn9@kuhp.kyoto-u.ac.jp

* Correspondence: sakai.michi.7v@gmail.com; Tel.: +81-75-753-9477

$\dagger$ Members of BiDAME (Big Data Analysis of Medical Care for the Older in Kyoto): Fukuhara S, Fukuma S, Imanaka Y, Muto M, Okuno Y, Tamura H, Tanaka S, Yamamoto Y, Yanagida M, Funakoshi T, Goto Y, Goto E, Hanaki N, Hiragi S, Ikenoue T, Iwao T, Kawakami K, Kondo N, Kunisawa S, Mori Y, Nakatsui M, Neff Y, Ohtera S, Okamoto K, Otsubo T, Saito H, Saito Y, Sakai M, Sato I, Seto K, Shimizu S, Takahashi Y, Yamashita K, Yoshida S, in Kyoto University Hospital/Kyoto University Graduate School of Medicine, School of Public Health, Kyoto, Japan.

Abstract: The administration of intensive end-of-life care just before death in older patients has become a major policy concern, as it increases medical costs; however, care intensity does not necessarily indicate quality. This study aimed to describe the temporal trends in the administration of life-sustaining treatments (LSTs) and intensive care unit (ICU) admissions just before death in older inpatients in Japan. We utilized the National Database of Health Insurance Claims and Specific Health Checkups of Japan (NDB). Inpatients who were aged $\geq 65$ years and died in October of 2012, 2013, or 2014 were analyzed. The numbers of decedents in 2012, 2013, and 2014 were 3362, 3473, and 3516, respectively. The frequencies of receiving cardiopulmonary resuscitation (CPR) $(11.0 \%$ to $8.3 \%)$, mechanical ventilation (MV) $(13.1 \%$ to $9.8 \%)$, central venous catheter (CVC) insertion $(10.6 \%$ to $7.8 \%$ ), and ICU admission (9.1\% to 7.8\%), declined between 2012 and 2014 . After adjusting for age, sex, and type of ward, the declining trends persisted for CPR, MV, and CVC insertion relative to the frequencies in 2012. Our results indicate that the administration of LST just before death in older inpatients in Japan decreased from 2012 to 2014.

Keywords: aged; older adults; health insurance claims; end-of-life care

\section{Introduction}

As populations around the world are rapidly ageing [1], the nature, quality, and costs of end-of-life care have attracted considerable interest [2-8]. The use of intensive end-of-life care just before the death of older patients has become a major policy concern, as it is considered a factor that increases medical costs [9]; however, care intensity does not necessarily indicate quality [10]. Since the late 1980s, ethical, legal, and social issues 
related to the withholding or withdrawal of intensive end-of-life care have been discussed in developed countries. In the 2000s, multiple policies and programs attempted to improve care at the end of life in the United States and European countries [11-14]. Japan has one of the world's most elderly societies, with a high mortality rate [15]. In Japan, the proportion of people aged 65 years or older was $28.4 \%$, and the mortality rate was 11.2 per 1000 population in 2019 [16]. Japan has also developed end-of-life care policies, such as guidelines on the decision-making process for care in the last stage of life [17] and hospice and palliative services [18]; other Asian counties, such as Korea [19] and Taiwan [20], have also developed end-of-life care policies. Research on temporal trends in the real-world practices regarding intensive care before death in older patients is now needed to examine the impact of these continued efforts in many countries.

A previous study in the U.S. targeting Medicare recipients who died between 1985 and 1999 showed that the proportion of decedents admitted to the ICU and treated with intensive procedures (e.g., feeding tube placements, intubations/tracheostomies, and receiving cardiopulmonary resuscitation increased [3]. However, between 2000 and 2015, there was an initial increase followed by a stabilization of the ICU admission rate [21]. Data from Washington State Death Certificates and the University of Washington medicine data warehouse, which includes clinical and administrative information from a university medical center, indicated that ICU admissions in the last 30 days of life significantly decreased from 2010 to 2015 among patients 65 years and older, suggesting the impact of the increased penetration of advance care planning and palliative care programs [22]. In the population-level cohort study of Canadian adults who died between 2004 and 2015, the proportion of patients admitted to the ICU in the last 6 months of life did not change, whereas the proportion receiving mechanical ventilation increased over the course of the 11 years [23]. A reliance on medical facilities to provide end-of-life care and a shortage of palliative, hospice or home-based care within the Canadian healthcare system were suggested as reasons for these trends [23]. However, less is known about the temporal trends in intensive care before death in the older Asian population.

Furthermore, limited evidence exists regarding the real-world practice with respect to intensive care "just before death" among older patients. According to a systematic review of studies of end-of-life resource utilization using health administrative data, the most common period defined as the end of life was the last 6 or 12 months [6]. As illness trajectories are quite variable over a long period of time before death [24], studies using longer periods may include treatments administered to patients who are not yet in the last stage of life. Thus, it is necessary to use a shorter period to elucidate the practices with regard to the provision of care just before death.

In this study, we aimed to describe the frequency of and temporal trends in the provision of intensive care just before death among older Japanese inpatients at the national level using the National Database of Health Insurance Claims and Specific Health Checkups of Japan (NDB), which contains almost $100 \%$ of the digitized health insurance claims [25].

\section{Materials and Methods}

\subsection{Definitions}

We defined the end-of-life as a specific period of time before death, which was recorded in health insurance claims data. Based on systematic reviews of studies that measured the intensity of end-of-life care [2,6], we defined intensive end-of-life care as receiving the following life-sustaining treatments (LSTs): cardiopulmonary resuscitation (CPR), mechanical ventilation (MV), and central venous catheter insertion (CVC) insertion or ICU admission.

\subsection{Study Design and Data Source}

We conducted a repeated cross-sectional study using data from the National Database of Health Insurance Claims and Specific Health Checkups of Japan (NDB) [25]. In Japan, all persons are required to be covered by public health insurance. As the NDB contains 
almost $100 \%$ of the digitized health insurance claims issued after the 2009 fiscal year, its use enables the evaluation of the real-world care practices in nearly the entire older Japanese population [26]. NDB data are untraceable and anonymized. The Ministry of Health, Labour and Welfare provides an NDB sampling dataset (NDB-SD) randomly sampled from $10 \%$ of the inpatient health insurance claims in the NDB for October, in which seasonal differences in healthcare utilization are not significant for research use. Because the date of administration is not recorded in claims issued before the 2012 fiscal year, we could not identify care practices in the last days of life before 2012. Thus, we used NDB-SD claims data issued from 2012 to 2014.

\subsection{Subjects}

The study subjects were deceased patients aged $\geq 65$ years who had been admitted to a hospital in October of 2012, 2013, or 2014 for $\geq 7$ days. As approximately $80 \%$ of care before death in Japan occurs in medical institutions, which is higher than in other countries [16], we focused on LSTs administered to hospitalized patients. Deceased patients were identified based on the hospitalization outcomes recorded in the claims, which allowed us to identify in-hospital mortality from claims data with a high degree of accuracy [27].

\subsection{Response Variables}

The response variables were the administration of CPR, the use of MV, CVC insertion and ICU admission in the last 7 days of life. We considered the administration of LSTs in the 7 days before death. Data on each LST were obtained from inpatient health insurance claims. CPR was either non-open cardiac massage, countershock, or life-saving endotracheal intubation. MV was either artificial respiration for life prolongation (invasive positive pressure ventilation, IPPV; noninvasive positive pressure ventilation, NPPV) or assisted ventilation for palliation, since we could not distinguish life-prolonging ventilation from other ventilation procedures due to the rules for reimbursement. ICU admissions were calculated from reimbursements for ICU admissions submitted by institutions providing acute care or emergency care.

\subsection{Variables Used for Adjustment}

We included age, sex, cancer diagnosis, and type of ward as factors for adjustment. Age was categorized into 65 to 74 years, 75 to 84 years, 85 to 94 years, and $\geq 95$ years. We included cancer diagnoses because reimbursement incentives for palliative care applied to only cancer under the Japanese health insurance system could affect the practices regarding the administration of LSTs and ICU admissions. Cancer diagnoses were identified from the diagnoses recorded in the claims issued in the last month of life, i.e., October of each year. The types of wards in which patients died were categorized into general wards, long-term care wards, wards for psychiatric diseases, and wards for tuberculosis. General wards mainly provided acute care. Long-term care wards provided long-term care for patients with severe physical and cognitive problems.

\subsection{Statistical Analysis}

We applied the Cochran-Armitage trend test for detecting a temporal trend in the frequencies of LSTs and ICU admissions as we assume linear trend. The Cochran-Armitage (CA) test is used to test whether there is a linear trend when the response is binary. The null hypothesis is that the binomial proportion is the same for all levels of the explanatory variable. It is commonly used in epidemiology to test for temporal trend in healthcare utilizations. We used the administration of each LST and ICU admission as binary categorical response variables and the year of death as explanatory variable. We also conducted logistic regression analysis using the administration of each LST and ICU admission as response variables and the year of death, age, sex, cancer diagnosis, and type of ward as categorical variables for adjustment. As we assume that linear trend is different from 2012 to 2013 and 2013 to 2014, we treated the year of death as a categorical variable using 2012 
as the reference year. We used SPSS version 23 (SPSS Inc., Chicago, IL, USA) for Windows for the analysis. We set the significance level of each test to $5 \%$.

\section{Results}

\subsection{Patient Characteristics}

The numbers of hospitalized patients included in the NDB-SD for October 2012, October 2013, and October 2014 were 225,650, 225,709, and 227,970, respectively. The numbers of eligible patients for the analysis in each year were 3362, 3473, and 3516, respectively. We excluded patients aged $<65$ years $(n=2012: 83,380,2013: 80,956,2014$ : 79,423 ), patients who had an outcome other than death (i.e., continued, cure, termination, and transferred) ( $n=2012: 136,852,2013: 139,100,2014: 142,861)$, patients with fewer than 7 days of hospitalization ( $n=2012: 2054,2013: 2178,2014: 2168)$, and patients with no charge records for treatment ( $n=2012: 2$, 2013: 2, 2014: 2 ).

Comparisons of patient characteristics in each year are shown in Table 1. The proportions of male patients, the age distributions, and proportions of patients who received care in each ward were constant over the study period. Nearly half of the patients (44.2\%, $n=1486$ in 2012, 45.3\%, $n=1575$ in 2013,48.2\%, $n=1694$ in 2014) died at 85 years of age or older.

Table 1. Characteristics of deceased patients in October of 2012-2014.

\begin{tabular}{cccccccc}
\hline & & $\mathbf{2 0 1 2}$ & & $\mathbf{2 0 1 3}$ & \multicolumn{3}{c}{$\mathbf{2 0 1 4}$} \\
\hline \multirow{3}{*}{ Total } & & $N$ & $\%$ & $N$ & $\%$ & $N$ & $\%$ \\
Age, years & & 3362 & & 3473 & & 3516 & \\
& $65-74$ & 632 & $18.8 \%$ & 600 & $17.3 \%$ & 595 & $16.9 \%$ \\
& $75-84$ & 1244 & $37.0 \%$ & 1298 & $37.4 \%$ & 1227 & $34.9 \%$ \\
Sex & $85-94$ & 1233 & $36.7 \%$ & 1309 & $37.7 \%$ & 1391 & $39.6 \%$ \\
& $\geq 95$ & 253 & $7.5 \%$ & 266 & $7.7 \%$ & 303 & $8.6 \%$ \\
Cancer & Male & 1783 & $53.0 \%$ & 1849 & $53.2 \%$ & 1876 & $53.4 \%$ \\
Diagnosis & Female & 1579 & $47.0 \%$ & 1624 & $46.8 \%$ & 1640 & $46.6 \%$ \\
Ward type & Cancer & 1216 & $36.2 \%$ & 1326 & $38.2 \%$ & 1273 & $36.2 \%$ \\
& Non-cancer & 2146 & $63.8 \%$ & 2147 & $61.8 \%$ & 2243 & $63.8 \%$ \\
& General & 2582 & $76.8 \%$ & 2634 & $75.8 \%$ & 2607 & $74.1 \%$ \\
& Long-term care & 671 & $20.0 \%$ & 732 & $21.1 \%$ & 782 & $22.2 \%$ \\
& Psychiatric & 93 & $2.8 \%$ & 93 & $2.7 \%$ & 115 & $3.3 \%$ \\
& Tuberculosis & 12 & $0.4 \%$ & 11 & $0.3 \%$ & 8 & $0.2 \%$ \\
\hline
\end{tabular}

\subsection{Frequencies and Yearly Trends in the Administration of LSTs and ICU Admissions}

The frequencies of the administration of CPR $(11.0 \%$ to $8.3 \%$; $p$ for trend $<0.001)$, the use of MV (13.1\% to $9.8 \%$; $p$ for trend $<0.001)$, CVC insertion $(10.6 \%$ to $7.8 \%$; $p$ for trend $<0.001$ ), and ICU admission (9.1\% to 7.8\%; $p$ for trend =0.29) declined from 2012 to 2014 (Table 2, Figure 1). Subgroup analyses stratified by age, sex, cancer diagnosis, and ward also indicated decreasing trends in almost all subgroups (excluding the psychiatric and tuberculosis wards, which had fewer patients). Larger declining trends in the administration of $\mathrm{CPR}$ and use of MV were identified for patients $\geq 95$ years than for those aged between 65 and 74 years. 
Table 2. Annual trends in the administration of life-sustaining treatments and intensive care unit admissions in the last 7 days of life from 2012 to 2014.

\begin{tabular}{|c|c|c|c|c|c|c|c|c|c|c|c|c|c|c|c|c|c|}
\hline & & CPR & & & & MV & & & & CVC & & & & ICU & & & \\
\hline & & 2012 & 2013 & 2014 & & 2012 & 2013 & 2014 & & 2012 & 2013 & 2014 & & 2012 & 2013 & 2014 & \\
\hline & & $\%$ & $\%$ & $\%$ & $p$ & $\%$ & $\%$ & $\%$ & $p$ & $\%$ & $\%$ & $\%$ & $p$ & $\%$ & $\%$ & $\%$ & $p$ \\
\hline Total & & 11.0 & 9.6 & 8.3 & $* * *$ & 13.1 & 11.4 & 9.8 & $* * *$ & 10.6 & 8.7 & 7.8 & $* * *$ & 9.1 & 8.5 & 7.8 & 0.29 \\
\hline \multirow[t]{5}{*}{ Age } & & & & & & & & & & & & & & & & & \\
\hline & $65-74$ & 9.8 & 9.2 & 9.7 & 0.96 & 16.5 & 14.2 & 13.4 & 0.13 & 13.6 & 11.7 & 8.7 & 0.01 & 12.6 & 11.6 & 9.1 & 0.20 \\
\hline & $75-84$ & 12.3 & 11.5 & 9.3 & 0.02 & 15.0 & 13.6 & 10.8 & $* *$ & 12.2 & 9.5 & 10.4 & 0.13 & 9.3 & 8.2 & 7.0 & 0.25 \\
\hline & 85-94 & 10.9 & 8.6 & 7.7 & $* *$ & 10.3 & 9.1 & 8.6 & 0.13 & 8.5 & 7.5 & 5.6 & $* *$ & 6.4 & 7.3 & 7.9 & 0.46 \\
\hline & $>95$ & 7.9 & 6.0 & 4.0 & 0.05 & 8.7 & 5.6 & 4.3 & 0.03 & 4.7 & 4.5 & 6.3 & 0.40 & 4.0 & 2.1 & 5.9 & 0.63 \\
\hline \multicolumn{18}{|l|}{ Sex } \\
\hline & Male & 12.1 & 9.6 & 9.0 & $* *$ & 14.5 & 12.6 & 11.2 & $* *$ & 12.2 & 9.7 & 8.2 & $* * *$ & 10.4 & 8.4 & 7.8 & 0.10 \\
\hline & Fem & 9.8 & 9.5 & 7.5 & 0.02 & 11.4 & 10.0 & 8.2 & $* *$ & 8.7 & 7.6 & 7.4 & 0.17 & 7.1 & 8.8 & 7.8 & 0.72 \\
\hline Cancer & Yes & 6.5 & 4.4 & 3.7 & $* *$ & 7.0 & 5.1 & 4.2 & $* *$ & 12.0 & 9.0 & 6.9 & $* * *$ & 4.1 & 2.7 & 1.8 & 0.05 \\
\hline Dx & No & 13.6 & 12.8 & 10.9 & 0.01 & 16.5 & 15.3 & 12.9 & $* *$ & 9.7 & 8.6 & 8.4 & 0.12 & 12.8 & 13.6 & 12.2 & 0.75 \\
\hline \multicolumn{18}{|l|}{ Wards } \\
\hline & Gen & 11.2 & 9.3 & 8.0 & $* * *$ & 14.6 & 12.6 & 11.2 & $* * *$ & 13.4 & 10.7 & 10.2 & $* * *$ & & & & $\mathrm{~N} / \mathrm{A}$ \\
\hline & LTC & 9.5 & 9.0 & 7.9 & 0.28 & 7.7 & 7.1 & 4.9 & 0.02 & 0.9 & 2.0 & 0.6 & 0.57 & & & & $\mathrm{~N} / \mathrm{A}$ \\
\hline & Psyc & 14.0 & 19.4 & 18.3 & 0.44 & 9.7 & 9.7 & 11.3 & 0.69 & 3.2 & 6.5 & 3.5 & 0.99 & & & & $\mathrm{~N} / \mathrm{A}$ \\
\hline & $\mathrm{TB}$ & 16.7 & 18.2 & 0.0 & 0.32 & 0.0 & 18.2 & 0.0 & 0.81 & 0.0 & 0.0 & 12.5 & 0.15 & & & & $\mathrm{~N} / \mathrm{A}$ \\
\hline
\end{tabular}

The value in the column named as "\%" represents the frequencies of administration of CPR, MV, CVC, and ICU admissions in each years. $p$ represents $p$-value for Cochran-Armitage trend test. The numbers of subjects in the analysis for administration of CPR, MV, and CVC in 2012, 2013, and 2014 were 3362, 3473, and 3516, respectively. The subjects in the analysis for ICU admissions were patients admitted to institutions with acute care or emergency care acute institutions which have ICU. The numbers of subjects in 2012, 2013, and 2014 were 1025,1018 , and 1018, respectively. Symbol: **: $p$-value $<0.01{ }^{* * *}: p$-value $<0.001$. Abbreviations: CPR: cardiopulmonary resuscitation, MV: mechanical ventilation, CVC: central venous catheter insertion, ICU: intensive care unit, Fem: Female, Cancer Dx: Cancer diagnosis, Gen: General ward, LTC: Long-term care ward, Psyc: Psychiatric ward, TB: Tuberculosis ward.

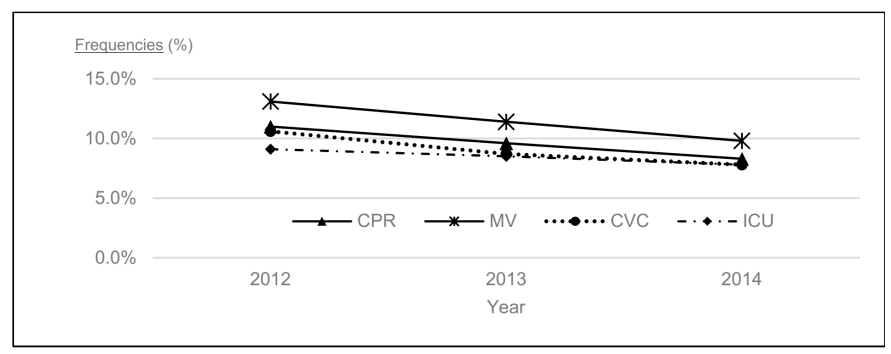

Figure 1. Annual trends in the administration of life-sustaining treatments and intensive care unit admissions in the last 7 days of life from 2012 to 2014 . The vertical line represents the frequencies of administration of CPR, MV, CVC, and ICU admissions and the horizontal one year. Abbreviations: CPR: cardiopulmonary resuscitation, $\mathrm{MV}$ : mechanical ventilation, CVC: central venous catheter insertion, ICU: intensive care unit.

After adjusting for age, sex, cancer diagnosis, and ward type with logistic regression analysis, significant declining trends persisted for the administration of CPR (in 2013, adjusted odds ratio (AOR) 0.88 [95\% CI 0.75-1.03]; in 2014, 0.74 [0.63-0.87]), the use of MV (in 2013, 0.89 [0.76-1.03]; in 2014, 0.74 [0.64-0.87]), and CVC insertion (in 2013, 0.82 [0.70-0.97]; in 2014, 0.75 [0.63-0.89]) relative to the values in 2012 (Table 3). 
Table 3. Annual decreases in the odds of receiving life-sustaining treatments and intensive care unit admission in the last 7 days of life from 2012 to 2014.

\begin{tabular}{|c|c|c|c|c|c|c|c|c|c|c|c|c|}
\hline & CPR & & & MV & & & CVC & & & ICU & & \\
\hline & AOR & CI & $p$ & AOR & CI & $p$ & AOR & CI & $p$ & AOR & CI & $p$ \\
\hline 2012 (ref) & & & & & - & & & & - & & & \\
\hline 2013 & 0.88 & [0.75-1.03] & 0.11 & 0.89 & [0.76-1.03] & 0.11 & 0.82 & [0.70-0.97] & 0.02 & 0.99 & [0.72-1.35] & 0.93 \\
\hline 2014 & 0.74 & {$[0.63-0.87]$} & $* * *$ & 0.74 & [0.64-0.87] & $* * *$ & 0.75 & [0.63-0.89] & $* * *$ & 0.88 & [0.64-1.21] & 0.43 \\
\hline
\end{tabular}

Symbol: ${ }^{* * *}: p$-value < 0.001. Abbreviations: AOR: adjusted odds ratio, CI: $95 \%$ confidence interval, ref.: reference. $p$ : $p$-value for logistic regression analysis using the administration of each LST and ICU admission as a binary categorical response variable and the year of death, age, sex, cancer diagnosis, and ward as categorical variables for adjustment. CPR: cardiopulmonary resuscitation, MV: mechanical ventilation, CVC: central venous catheter insertion, ICU: intensive care unit.

\section{Discussion}

We identified annual declining trends between 2012 and 2014 in the frequencies of the administration of CPR $(11.0 \%$ to $8.3 \%$, adjusted odds ratio in 2014 relative to 2012 (AOR) 0.74 [0.63-0.87]), the use of MV (13.1\% to 9.8\%, AOR 0.74 [0.64-0.87]), and CVC insertion (10.6\% to $7.8 \%$, AOR 0.75 [0.63-0.89]) just before death among patients aged $\geq 65$ years using nationally representative claims data. Larger declining trends in the administration of CPR were observed in patients $\geq 95$ years $(7.9 \%$ to $4.0 \%)$ than in those aged between 65 and 74 years $(9.8 \%$ to $9.7 \%)$.

Although the survey year, the period defined as the end of life, and study settings vary among studies, decreasing trends in intensive care are consistent with studies targeting decedents in Washington State in U.S. and in 14 European countries. Among older decedents in Washington State, ICU admissions in the last 30 days of life declined from 2010 to 2015 [22]. The increased penetration of advance care planning and palliative care since 2012 is suggested to have contributed to the decline [22]. Among patients who died in ICUs in 14 European countries, death without withholding LSTs significantly declined from 1999 to 2015 in accordance with the changes in European laws, recommendations and guidelines regarding end-of-life practices over the past decades [28]. Our results are also consistent with Japan's rank in the Quality of Death Index published by The Economist Intelligence Unit, which evaluates developing and developed countries in terms of palliative and healthcare environment, human resources, affordability of care, quality of care, and community engagement [7,8]. Japan was ranked 23rd among 40 countries in 2010 [7] and 14th among 80 countries in 2015 [8]. Two Asian counties, Taiwan (at position 6 in 2015) and Singapore (at position 12) which developed a strong and effective national palliative care policy framework ranked higher than in Japan and also improved in rank in 2015 than in 2010 [8]. On the other hand, the frequencies of LSTs and ICU admission before the death of patients aged 65 years or older remain lower in Japan than those in countries that reported the care intensity at the national level. ICU admissions in the last 30 days of decedents in 2015 Medicare and decedents in 2009 Korean National Health Insurance Service were $27.4 \%$ [21], and 26.3\% [19], respectively, whereas ICU admissions in the last 7 days in the present study were $7.8 \%$ in 2014. Administration of MV in the last 30 days of Korean decedents in 2009 was 19.5\% [19], whereas MV in the last 7 days in the present study were $9.8 \%$ in 2014 . Although the period defined as the end of life is longer than our study, differences in healthcare delivery systems may be also related to the discrepancy. Critical care services vary between countries in the number of beds. The number of ICU beds per 100,000 population in 2005 was 20.9 in the USA and 4.3 in Japan [29]. Korean healthcare delivery relies heavily on the private providers, leading to an increase in demands for intensive care [19].

The possible reason for the declines in the use of MV and CVC insertion in Japan is the improvements made to less invasive medical devices. Nasal high-flow therapy as an alternative to invasive positive pressure ventilation (IPPV) or noninvasive positive pressure ventilation (NPPV) and peripherally inserted central catheters (PICCs) as an 
alternative to CVCs might be related to these trends. However, the declining trend in the administration of CPR is worthy of attention, as improvements in medical devices are unlikely to be related to the frequency of the administration of CPR, which was identified based on reimbursement for either non-open cardiac massage, countershock, or life-saving endotracheal intubation. The larger declining trend in the administration of CPR in the group aged 95 years and older than in the group aged 65 to 74 years is also striking. As efforts to improve the process for decision making regarding resuscitation in older patients, the Ministry of Health, Labor and Welfare (MHLW) developed guidelines on the decision-making process pertaining to the last stage of life in 2007 [17]. In 2012, the Japan Geriatrics Society revised their position statement about terminal medicine and care for elderly individuals that had been published in 2001, promoting the use of advanced directives [30]. The MHLW also launched an education program related to engaging in endof-life discussions for healthcare professionals in 2014 [31]. According to opinion surveys targeting the Japanese public and medical workers in 2017 [32], awareness of advanced directives have increased for these 10 years. The decreasing trends in LSTs shown in our study might be attributed to these efforts. ICU admissions did not significantly decrease. The increase in the number of ICU bed from 2012 to 2014 in Japan [33] might lead to the increases in the demand for ICU admissions.

The decline in administration of LSTs in Japan was inconsistent with the increase in the total cost and the per capita cost of medical care for older population from 2012 to 2014 [34]. The impact of LST utilization on the total cost and the per capita cost of medical care for the population aged $\geq 65$ years might be limited because there is a discrepancy between the study population and evaluation periods for total cost and those used in our study (in the last 7 days for decedents). Expensive or highly advanced medical treatment, such as anticancer agents and long-term hospitalization [9], for older patients may be significantly attributed to the increase in total cost.

Although individual treatment preferences vary, the decline in LSTs just before death suggests a shift in patient- and family-centered end-of-life care. According to a systematic review of family satisfaction with end-of-life care, the absence of CPR before death is associated with a higher rating of the quality of death and dying by family [35]. Opinion surveys targeting the Japanese public and medical workers in 2017 indicated that the preference for withholding LSTs when there is no chance of improvement increased over a 10-year period [32]. A nationwide survey of bereaved families of cancer patients in Japan indicated that the presence of end-of-life discussions to plan care and pain-free or distress-free care in the last days of life are important determinants for quality of care [36]. These studies suggested that the decline in end-of-life care intensity suggests increasing patient and family satisfaction with the quality of death

The frequency of the administration of intensive care measures has been used to evaluate the nature and extent of resource utilization and the costs associated with end-oflife care [6]. Recent developments in large claims databases enabled us to obtain a picture of medical care practices just before death at the national level. Routinely collected claims data can be utilized at a lower cost to study large populations rather than primary data collections. Continuous evaluations of the trends in care can inform efforts to improve care practices.

The study has some limitations. First, because the date of administration is not recorded in claims issued before fiscal year 2012, we could not identify the administration of LSTs or ICU admissions in the last 7 days in the claims issued before 2012. Thus, we could not examine the practice of end-of-life care before 2012, when major policies leading to the dissemination of ACP were developed. We examined only 3 years, from 2012 to 2014. Long-term observations after 2014 are needed to verify the declining trends in the administration of intensive end-of-life care. Second, as our results relied on data from the health insurance claims database, we could not identify the usage of LSTs and ICU admissions not recorded on the submitted claims, e.g., due to a delay in charging. Furthermore, we could not analyze factors that might be associated with changes in practice, 
such as the cause of death, severity of disease, prior treatments before October of each year, and medical institution characteristics, due to restrictions on the claims used for billing purposes. We focused on intensive care "just before death" by evaluating care in the last 7 days of life. However, patients who were not yet in the last stage of life and benefitted from intensive care could also be included as study subjects. The shortage of medical resources for care might also contribute to the decline. Thus, we could neither examine the appropriateness of LSTs and ICU admissions nor conclude that our results indicate improvement of quality of end-of-life care.

\section{Conclusions}

We elucidated the changes in intensive care practices "just before death" among older patients through a focus on LSTs and ICU admissions in the last 7 days of life, which have not been sufficiently evaluated at the national level. Based on nationally representative claims data in Japan, declining trends in the administration of LSTs one week before death among older inpatients from 2012 to 2014 are shown. Further evidence for the practice of older patients in the dying phase is required. Since 2014, policies for further promoting palliative care and revisions of medical fees to improve end-of-life care have been implemented. Further study of trends after 2014 and continuous nationwide monitoring in care practice by utilizing administrative claims data can inform efforts to improve end-of-life care.

Author Contributions: Conceptualization: T.N. and BiDAME (Big Data Analysis of Medical Care for the Elderly in Kyoto); Methodology: M.S., S.O., T.I., T.U., Y.T., G.K., S.N., and T.N.; Software: M.S., S.O., T.I., Y.T.; Validation: M.S., S.O., T.I., T.U., Y.T., G.K. and T.N.; Formal analysis: M.S., S.O., T.I.; Investigation: M.S., S.O., T.I., Y.T., G.K., and T.N.; Resources: T.K. and T.N.; Data curation: M.S., S.O., and T.I.; Writing-original draft preparation: M.S., S.O., Y.T., G.K., and T.N.; Writing—review and editing: M.S., S.O., Y.T., G.K., T.K. and T.N.; Visualization: M.S.; Supervision: G.K., T.K., S.N., and T.N.; Project administration: Y.N., T.K., S.N., and T.N.; Funding acquisition: M.S., G.K., T.K., S.N., and T.N. All authors have read and agreed to the published version of the manuscript.

Funding: This work was supported by the Ministry of Health, Labour and Welfare Grant-in-Aid for Scientific Research (Research on Policy Planning and Evaluation) (H27-policy-strategy-013), the Institute for Health Economics and Policy (Grant for Young Researcher B, H28), the Japan Society for the Promotion of Science (Grant-in-Aid for Young Scientists, H29), the Ministry of Health, Labour and Welfare Grant-in-Aid for Scientific Research (Research on Policy Planning and Evaluation) (H29policy-strategy-005), and the Japan Society for the Promotion of Science (Grant-in-Aid for Scientific Research (A), H30). The funders had no role in the design of the study; in the collection, analyses, or interpretation of data; in the writing of the manuscript, or in the decision to publish the results.

Institutional Review Board Statement: The study was conducted according to the ethics guidelines for medical and health research involving human subjects and guidelines for the use of the National Database of Health Insurance Claims and Specific Health Checkups of Japan (NDB) issued by the Ministry of Health, Labour and Welfare, Government of Japan. The study protocol was approved by Kyoto University's research ethics committee (R0307-2).

Informed Consent Statement: Not applicable.

Data Availability Statement: Restrictions apply to the availability of these data. Data was obtained from the Ministry of Health, Labour and Welfare, and are not available without the permission of the Ministry of Health, Labour and Welfare.

Conflicts of Interest: The authors declare that they have no competing interests. The funders had no role in the design of the study; in the collection, analyses, or interpretation of data; in the writing of the manuscript, or in the decision to publish the results. Declarations of COI from each researcher are managed by Kyoto University, Kyoto University Hospital, and the Institute for Health Economics and Policy. 


\section{References}

1. World Health Organization. The Global Strategy and Action Plan on Ageing and Health. Available online: https://www.who. int/ageing/global-strategy/en/ (accessed on 1 February 2021).

2. Luta, X.; Maessen, M.; Egger, M.; Stuck, A.E.; Goodman, D.; Clough-Gorr, K.M. Measuring intensity of end of life care: A systematic review. PLoS ONE 2015, 10, e0123764. [CrossRef]

3. Barnato, A.E.; McClellan, M.B.; Kagay, C.R.; Garber, A.M. Trends in inpatient treatment intensity among Medicare beneficiaries at the end of life. Health Serv. Res. 2004, 39, 363-375. [CrossRef] [PubMed]

4. Lerolle, N.; Trinquart, L.; Bornstain, C.; Tadie, J.M.; Imbert, A.; Diehl, J.L.; Fagon, J.Y.; Guerot, E. Increased intensity of treatment and decreased mortality in elderly patients in an intensive care unit over a decade. Crit. Care Med. 2010, 38, 59-64. [CrossRef] [PubMed]

5. Wilson, D.M.; Thurston, A.; Lichlyter, B. Should the oldest-old be admitted to the intensive care unit and receive advanced life-supporting care? Crit. Care Med. 2010, 38, 303-304. [CrossRef]

6. Langton, J.M.; Blanch, B.; Drew, A.K.; Haas, M.; Ingham, J.M.; Pearson, S.A. Retrospective studies of end-of-life resource utilization and costs in cancer care using health administrative data: A systematic review. Palliat. Med. 2014, 28, 1167-1196. [CrossRef]

7. The Economist Intelligence Unit. The Quality of Death Ranking End-of-Life Care across the World. Available online: http: //www.lienfoundation.org/sites/default/files/qod_index_2.pdf (accessed on 1 February 2021).

8. The Economist Intelligence Unit. The 2015 Quality of Death Index Ranking Palliative Care across the World A Report by The Economist Intelligence Unit. Available online: http:/ / www.lienfoundation.org/sites/default/ files/2015\%20Quality\%20of\%20 Death\%20Report.pdf (accessed on 1 February 2021).

9. Fukawa, T. Inpatient Expenditure of the Decedent Elderly in Japan. Br. J. Med. Med. Res. 2016, 15, 1-10. [CrossRef]

10. Cardona-Morrell, M.; Kim, J.; Turner, R.M.; Anstey, M.; Mitchell, I.A.; Hillman, K. Non-beneficial treatments in hospital at the end of life: A systematic review on extent of the problem. Int. J. Qual. Health Care 2016, 28, 456-469. [CrossRef]

11. Institute of Medicine. Dying in America: Improving Quality and Honoring Individual Preferences Near the End of Life; The National Academics Press: Washington, DC, USA, 2015. [CrossRef]

12. British Medical Association. Withholding and Withdrawing Life-Prolonging Medical Treatment: Guidance for Decision Making; British Medical Association: Malden, MA, USA, 2007.

13. World Health Organization. Better Palliative Care for Older People. Available online: https://www.euro.who.int/_data/assets/ pdf_file/0009/98235/E82933.pdf (accessed on 1 February 2021).

14. Raphael, C.; Ahrens, J.; Fowler, N. Financing end-of-life care in the USA. J. R. Soc. Med. 2001, 94, 458-461, 457-466. [CrossRef]

15. The Population Division of the Department of Economic and Social Affairs of the United Nations Secretariat. The 2019 Revision of World Population Prospects. Available online: https:/ / population.un.org/wpp/DataQuery/ (accessed on 1 February 2021).

16. Ministry of Health, Labour and Welfare. FY 2019 Vital Statistics. Available online: https://www.mhlw.go.jp/toukei/saikin/hw / jinkou/kakutei19/index.html (accessed on 1 February 2021).

17. Ministry of Health, Labour and Welfare. Guideline on the Decision-Making Process for Medical and Nursing Care at the Last Stage of life. Available online: https:/ / www.mhlw.go.jp/ file/05-Shingikai-10801000-Iseikyoku-Soumuka/0000194860.pdf (accessed on 1 February 2021).

18. Asia-Pacific Hospice Palliative Care Network. Japan-Palliative Care Becoming the Norm. Available online: https://aphn.org/ japan-palliative-care-becoming-the-norm/ (accessed on 1 February 2021).

19. Kim, S.H.; Kang, S.; Song, M.K. Intensity of Care at the End of Life Among Older Adults in Korea. J. Palliat. Care 2018, 33, 47-52. [CrossRef]

20. Lai, C.F.; Tsai, H.B.; Hsu, S.H.; Chiang, C.K.; Huang, J.W.; Huang, S.J. Withdrawal from long-term hemodialysis in patients with end-stage renal disease in Taiwan. J. Formos Med. Assoc. 2013, 112, 589-599. [CrossRef]

21. Teno, J.M.; Gozalo, P.; Trivedi, A.N.; Bunker, J.; Lima, J.; Ogarek, J.; Mor, V. Site of Death, Place of Care, and Health Care Transitions Among US Medicare Beneficiaries, 2000-2015. JAMA 2018, 320, 264-271. [CrossRef] [PubMed]

22. Sathitratanacheewin, S.; Engelberg, R.A.; Downey, L.; Lee, R.Y.; Fausto, J.A.; Starks, H.; Dunlap, B.; Sibley, J.; Lober, W.; Loggers, E.T.; et al. Temporal Trends Between 2010 and 2015 in Intensity of Care at End-of-Life for Patients With Chronic Illness: Influence of Age Under vs. Over 65 Years. J. Pain Symptom. Manag. 2018, 55, 75-81. [CrossRef]

23. Hill, A.D.; Stukel, T.A.; Fu, L.; Scales, D.C.; Laupacis, A.; Rubenfeld, G.D.; Wunsch, H.; Downar, J.; Rockwood, K.; Heyland, D.K.; et al. Trends in site of death and health care utilization at the end of life: A population-based cohort study. CMAJ Open 2019, 7, E306-E315. [CrossRef]

24. Lunney, J.R.; Lynn, J.; Foley, D.J.; Lipson, S.; Guralnik, J.M. Patterns of functional decline at the end of life. JAMA 2003, 289, 2387-2392. [CrossRef]

25. Kato, G. History of the Secondary Use of National Database of Health Insurance Claims and Specific Health Checkups of Japan(NDB). Trans. Jpn. Soc. Med. Biol. Eng. 2017, 55, 143-150. [CrossRef]

26. Nakayama, T.; Imanaka, Y.; Okuno, Y.; Kato, G.; Kuroda, T.; Goto, R.; Tanaka, S.; Tamura, H.; Fukuhara, S.; Fukuma, S.; et al. Analysis of the evidence-practice gap to facilitate proper medical care for the elderly: Investigation, using databases, of utilization measures for National Database of Health Insurance Claims and Specific Health Checkups of Japan (NDB). Environ. Health Prev. Med. 2017, 22, 51. [CrossRef] 
27. Sakai, M.; Ohtera, S.; Iwao, T.; Neff, Y.; Kato, G.; Takahashi, Y.; Nakayama, T.; BiDame. Validation of claims data to identify death among aged persons utilizing enrollment data from health insurance unions. Environ. Health Prev. Med. 2019, 24, 63. [CrossRef]

28. Sprung, C.L.; Ricou, B.; Hartog, C.S.; Maia, P.; Mentzelopoulos, S.D.; Weiss, M.; Levin, P.D.; Galarza, L.; de la Guardia, V.; Schefold, J.C.; et al. Changes in End-of-Life Practices in European Intensive Care Units From 1999 to 2016. JAMA 2019, 322, 1692-1704. [CrossRef] [PubMed]

29. Wunsch, H.; Angus, D.C.; Harrison, D.A.; Collange, O.; Fowler, R.; Hoste, E.A.; de Keizer, N.F.; Kersten, A.; Linde-Zwirble, W.T.; Sandiumenge, A.; et al. Variation in critical care services across North America and Western Europe. Crit. Care Med. 2008, 36, 2787-e8. [CrossRef] [PubMed]

30. Japanese Geriatric Society Ethics Committee; Iijima, S.; Aida, N.; Ito, H.; Endo, H.; Ohrui, T.; Sodei, T.; Toba, K.; Hara, K.; Momose, Y.; et al. Position statement from the Japan Geriatrics Society 2012: End-of-life care for the elderly. Geriatr. Gerontol. Int. 2014, 14, 735-739. [CrossRef] [PubMed]

31. Ohama, E.; Fukui, S. A Review of Advance Care Planning in Research and Clinical Settings. Palliat. Care Res. 2019, 14, 269-279. [CrossRef]

32. Ministry of Health, Labour and Welfare. National Survey on End-of-Life Health Care Report in 2017. Available online: https:/ / www.mhlw.go.jp/toukei/list/saisyuiryo_a.html (accessed on 1 February 2021).

33. Ministry of Health, Labour and Welfare. FY 2016 Survey of Medical Institutions. Available online: https:/ / www.e-stat.go.jp/statsearch $/$ files? page $=1 \&$ layout $=$ datalist $\&$ toukei $=00450021 \&$ tstat $=000001030908 \&$ cycle $=7 \&$ year $=20140 \&$ month $=0 \&$ tclass $1=00000$ 1077195\&tclass2=000001077196 (accessed on 1 February 2021).

34. Ministry of Health, Labour and Welfare. FY 2016 Overview of National Medical Expenses. Available online: https://www.mhlw. go.jp/toukei/saikin/hw/k-iryohi/14/ (accessed on 1 February 2021).

35. Hinkle, L.J.; Bosslet, G.T.; Torke, A.M. Factors associated with family satisfaction with end-of-life care in the ICU: A systematic review. Chest 2015, 147, 82-93. [CrossRef] [PubMed]

36. Shiimzu, M.; Aoyama, M.; Morita, T.; Morita, T.; Tsuneto, S.; Shima, Y.; Miyashita, M. The Japan Hospice and Palliative Care Evaluation 2 study (J-HOPE2 study). Palliat. Care Res. 2016, 11, 254-264. [CrossRef] 